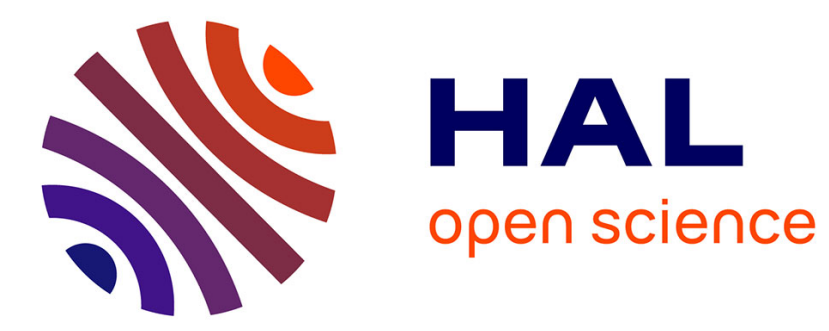

\title{
Carbon-coated structured supports. Preparation and use for nitrobenzene hydrogenation
}

Philippe Rodriguez, Florica Simescu-Lazar, Valérie Meille, Thierno Bah, Stéphanie Pallier, Isabelle Fournel

\section{- To cite this version:}

Philippe Rodriguez, Florica Simescu-Lazar, Valérie Meille, Thierno Bah, Stéphanie Pallier, et al.. Carbon-coated structured supports. Preparation and use for nitrobenzene hydrogenation. Applied Catalysis A : General, 2012, 427-428, pp.66-72. 10.1016/j.apcata.2012.03.031 . hal-01930895

\section{HAL Id: hal-01930895 https://univ-lyon1.hal.science/hal-01930895}

Submitted on 9 Apr 2019

HAL is a multi-disciplinary open access archive for the deposit and dissemination of scientific research documents, whether they are published or not. The documents may come from teaching and research institutions in France or abroad, or from public or private research centers.
L'archive ouverte pluridisciplinaire HAL, est destinée au dépôt et à la diffusion de documents scientifiques de niveau recherche, publiés ou non, émanant des établissements d'enseignement et de recherche français ou étrangers, des laboratoires publics ou privés. 


\title{
Carbon-coated structured supports. Preparation and use for nitrobenzene hydrogenation
}

\author{
Philippe Rodriguez, Florica Simescu-Lazar, Valérie Meille*, Thierno Bah, \\ Stéphanie Pallier, Isabelle Fournel \\ Université de Lyon, Institut de Chimie de Lyon, Laboratoire de Génie des Procédés \\ Catalytiques, CNRS, CPE Lyon, 43 bd du 11 novembre 1918, BP 82077, 69616 \\ Villeurbanne cedex, France
}

\begin{abstract}
Whereas carbon is a major catalyst support, namely in pharmaceutical industry, its immobilisation on structured objects has scarcely been studied. This article presents the comparison of two methods aiming at coating ceramic and metallic supports with a carbon layer. The method involving a suspension of black carbon is easy to use but leads to less adherent layers than the method involving the carbonization of poly(furfuryl alcohol). On the other hand, the former method is the one that allows to prepare more active catalysts for nitrobenzene hydrogenation. Then, the suspension formulation has been improved to enhance the carbon adhesion.
\end{abstract}

Key words: Carbon washcoating, Resin, Structured catalytic reactors, Stainless steel, Foam, Slurry, Nitrobenzene hydrogenation

\section{Introduction}

Among the variety of catalyst supports, carbon is one of the preferred ones, but its immobilisation on structured surfaces is much less studied than that of many other supports, e.g. alumina because of smaller interactions between the support and the coating [1]. Whereas several ways to obtain oxide-coated objects have been described [1-3], few can be adapted to ob-

\footnotetext{
*Corresponding author

Email address: vme@lgpc.cpe.fr, tel: +33 (0)4 72431755 - Fax: +33 (0) 472431673 (Valérie Meille)
} 
tain carbon-coated objects. The suspension method (dip-coating in a slurry of particles) and the electrophoretic deposition would possibly adapt well. However, the deposition of carbon with these methods based on a slurry of carbon particles has been scarcely used for catalysis purposes. Some examples are reported concerning sensors [4] or composite materials [5].

Concerning catalysis applications, most of the publications deal with the use of a resin as the carbon precursor. Since the pioneering work of Hucke [6] concerning the preparation of carbonaceous structures, carbon coating from a polymeric resin has been extensively studied and described for ceramic monoliths $[7,8]$ and ceramic foams $[9,10]$. However, by this method, very few articles deal with carbon deposition on non-ceramic structures. Schimpf et al. [11] describe the coating of AlMg microchannels $(0.3 \mathrm{~mm} \times 0.7 \mathrm{~mm}$ x $50 \mathrm{~mm}$ ), Acharya et al. [12] the coating of stainless steel disks by spraycoating to obtain membranes, Hajiesmaili et al. [13] the preparation of carbon foams by shape memory synthesis. A hybrid procedure has been used by Garcia-Bordeje et al. [14] to obtain activated carbon on monoliths. The monoliths were dipped in a mixture of polymer and carbon powder. The main other method reported in the literature is the direct growing of carbon nanofibers on substrates. Again, this method has mainly been used to coat ceramic monoliths [15-17]. One recent publication concerns the way to grow carbon nanofibers on stainless steel microreactors. The method is elegant but requires many successive steps [18].

In our work, we have tried to extend the use of resin coating to other families of structured surfaces, such as stainless steel foams, grids and plates. We have also tried to use a simple suspension method based on a slurry of commercial carbon. Both methods have been compared in terms of carbon loading and adherence on different materials. The carbon-coated ceramic objects have been impregnated with a palladium precursor and used in nitrobenzene hydrogenation to check their catalytic performances. The same reaction was used by Machado et al. [19] to demonstrate the possible replacement of slurry catalysts by monolith catalysts in the G/L/S synthesis of fine chemicals. 


\section{Experimental}

\subsection{Chemicals}

\subsubsection{Polymerisation method}

The starting chemicals were furfuryl alcohol (99\%, Aldrich), ethylene glycol (Acros) (referred to as EG), polyethylene glycol $\left(\mathrm{M}_{w} 200\right.$, Acros) (referred to as PEG) and nitric acid (65\%, provided by Carlo Erba). $\mathrm{H}_{2} \mathrm{O}_{2}$ at $35 \%$ was provided by Acros.

\subsubsection{Suspension method}

Vulcan XC72 powder (Cabot Corp.) was used as the carbon support (carbon black). Triton X-100 (Polyethylene glycol octylphenyl ether) was provided by Acros. Hydroxy-propyl-cellulose, dextrine and sucrose are SigmaAldrich products.

\subsubsection{Palladium precursor}

Palladium chloride (Sigma-Aldrich) was used to impregnate the carbon layers.

\subsection{Substrates and their pretreatments}

Plates of AISI 316L stainless steel (ThyssenKrupp), $50 \mathrm{~mm}$ long, $25 \mathrm{~mm}$ wide and $1 \mathrm{~mm}$ thick, about $10 \mathrm{~g}$, were used as non structured supports for preliminary tests. Stainless steel foams were purchased from Porvair Advanced Materials. $40 \mathrm{~mm}$ long, $10 \mathrm{~mm}$ wide and $10 \mathrm{~mm}$ thick pieces were cut in a 40 PPI foam of $5.2 \%$ density.

Most of the stainless steel (SS) substrates were pretreated according to the following procedure (from [20]). First, substrates were degreased in acetone for 15 min under sonication and then a heat treatment was performed. The furnace temperature was increased at a ramp rate of $2{ }^{\circ} \mathrm{C} / \mathrm{min}$ until it reached $500{ }^{\circ} \mathrm{C}$ and was held at this temperature for $4 \mathrm{~h}$, finally the furnace was allowed to cool down naturally at room temperature. After the heat treatment, stainless steel substrates were chemically treated by immersion in a sulphuric acid solution (30 wt.\%) during $3 \mathrm{~h}$. In order to eliminate acidic traces before the coating, substrates were immersed two times in distilled water under sonication during $30 \mathrm{~min}$. Finally, they were dried at $100{ }^{\circ} \mathrm{C}$ for $1 \mathrm{~h}$. The cordierite monolith pieces supplied by Corning were cut to form a rectangular parallelepiped (approx. $5 \mathrm{~cm} \times 1 \mathrm{~cm} \mathrm{x} 1 \mathrm{~cm}$ ); the wall thickness was $\sim 0.65 \mathrm{~mm}$, and the cell dimension corresponded to 9 cells. $\mathrm{cm}^{-2}$ (i.e. 
$64 \mathrm{cpsi}$ ). Each piece weighed about $4.5 \mathrm{~g}$. Before the catalyst deposition, the cordierite monolith pieces were sonicated in ethanol for 15 min and dried for $1 \mathrm{~h}$ at $100{ }^{\circ} \mathrm{C}$.

\subsection{Characterisation methods}

Concerning the carbon layer characterisation, BET measurements have been performed with a Micromeritics ASAP 2020 apparatus by physisorption of nitrogen at $-196{ }^{\circ} \mathrm{C}$. Before analysis, the samples were outgased at $300{ }^{\circ} \mathrm{C}$ during 4 hours. The pore diameter is an average pore diameter calculated from $4 V_{P} / S_{B E T}$ (cylindric pores). The micropore volume is calculated from t-plot curve.

On stainless steel plates, the carbon layer thickness have been measured with a Mitutoyo micrometer (ref. MDC-lite, $-\mathrm{S}$ ).

SEM observations were performed using a TM-1000 Tabletop Microscope from Hitachi High-Technologies.

On all the samples, the amount of carbon is obtained by weighing the object before and after coating and calcination.

The adherence of the carbon layer was evaluated by immersion of the washcoated object and further ultra-sonic treatment (Transsonic 275/H, $35 \mathrm{kHz}$ ) during one minute in a beaker containing heptane (test A) or water (test B). The surface acid functions of the carbon layer have been determined by acidbase titration according to the Boehm method [21]. The objective was not to discriminate between various types of functional groups and only one strong base was used instead of bases with various basicities. The carbon material is stirred with a known volume and concentration of sodium hydroxide during 24 hours. After filtration, the residual sodium hydroxide is back-titrated by a chlorhydric acid solution. The result is expressed in amount of acid functions per gram of carbon $(\mathrm{mmol} / \mathrm{g})$.

\subsection{Coating procedure}

\subsubsection{Polymerisation method}

A standard coating solution is prepared as follows: a mixture containing furfuryl alcohol $(10 \mathrm{~mL})$, as carbon precursor, and EG or PEG $(5 \mathrm{~mL})$, as texturing agent, is cooled at $0-5{ }^{\circ} \mathrm{C}$. Nitric acid $(0.25 \mathrm{~mL}$, as polymerisation catalyst) is added stepwise, under stirring, every $1.5 \mathrm{~min}, 25 \mu \mathrm{L}$ each time, maintaining the temperature below $5{ }^{\circ} \mathrm{C}$. After returning at room temperature, the stirring is maintained during 30 to 80 minutes. Then, the objects are immersed in the polymeric solution. In the polymerization method, when 
stainless steel plates are used, there is nearly no excess of liquid solution to evacuate if the viscosity of the polymeric solution is well controlled. In that case, only one drop of excess polymeric solution is removed by gravity. For cordierite monoliths and foams, the excess of polymeric solution is evacuated by capillarity using an absorbent paper.

Further polymerisation of the coated objects is performed at $80{ }^{\circ} \mathrm{C}$ under air $(0.5 \mathrm{~L} / \mathrm{min})$ during 2 hours. Then, the polymer is carbonised at $550{ }^{\circ} \mathrm{C}$ under nitrogen flow $(0.5 \mathrm{~L} / \mathrm{min})$ during 2 hours.

\subsubsection{Suspension method}

The standard suspension is prepared as follows: $27 \mathrm{~g}$ of Vulcan XC72, $180 \mathrm{~mL}$ of water and $5 \mathrm{~mL}$ of Triton X-100 are stirred together and the suspension is kept in an ultrasound apparatus during 50 minutes at room temperature. Hydroxy-propyl-cellulose, dextrine or sucrose have sometimes been used as suspension dispersants. The objects to coat are then immersed in the suspension and the excess liquid is evacuated. After a drying step performed at $80{ }^{\circ} \mathrm{C}$, the dispersant is decomposed during calcination at $550{ }^{\circ} \mathrm{C}$ under nitrogen flow $(0.5 \mathrm{~L} / \mathrm{min})$ during 2 hours.

\subsection{Carbon activation}

Using the polymerisation method (poly) and prior to catalyst deposition, different methods to increase the support porosity and/or functionalize the surface were tested. The treatment named poly-air corresponds to a preactivation method consisting in burning a part of the carbon and aiming at increasing the pore volume. It was performed using an air flow at $320{ }^{\circ} \mathrm{C}$ for 3 h. Further means to create some oxygenated active sites on the surface consisted in, first, using an air $/ \mathrm{H}_{2} \mathrm{O}$ flow at $320{ }^{\circ} \mathrm{C}$ for $6 \mathrm{~h}$ (named polyair $/ \mathrm{H}_{2} \mathrm{O}$ ). In another method, carbon-coated structures were immersed in $\mathrm{H}_{2} \mathrm{O}_{2}$ solution (35\%) during $24 \mathrm{~h}$ (named poly- $\mathrm{H}_{2} \mathrm{O}_{2}$ ). The reference polyair- $\mathrm{H}_{2} \mathrm{O}_{2}$ stands for a preactivation with air followed by a treatment in $\mathrm{H}_{2} \mathrm{O}_{2}$.

\subsection{Catalysts}

Two kinds of catalytic samples were prepared, both were obtained by impregnation with an acidic solution $(0.4 \mathrm{~N} \mathrm{HCl})$ of palladium chloride. The first samples (Family a) were powder shape obtained by crushing some carbon-coated monoliths. The amount of Pd salt was calculated to obtain

carbon with a known concentration of palladium. The powder was contacted 
during 24 hours in the Pd solution and the excess solvent was then evaporated. All the Pd salt was then deposited on the support (chemisorbed and physisorbed). The second kind of samples (Family b) were entire coated objects (monoliths or foams of millimetric dimensions). They were just dipped into a $\mathrm{PdCl}_{2}$ solution during 4 hours and removed from the excess solution. In the latter case, $\mathrm{Pd}$ was chemisorbed but the amount of $\mathrm{Pd}$ on carbon was a priori unknown. ICP-AES analysis of the initial and final concentration of $\mathrm{Pd}$ in the $\mathrm{PdCl}_{2}$ solution allowed to quantify a posteriori the actual $\mathrm{Pd}$ loading (with an estimated uncertainty of $20 \%$ ) of the samples. In both cases, the $\mathrm{Pd}$ precursor was finally decomposed at $550{ }^{\circ} \mathrm{C}$ under nitrogen flow during 2 hours. The $\mathrm{Pd} / \mathrm{C}$ catalyst was then reduced under hydrogen flow at $200{ }^{\circ} \mathrm{C}$ during 3 hours.

\subsection{Hydrogenation reaction}

The catalytic hydrogenation of nitrobenzene was used to evaluate the performances of the prepared $\mathrm{Pd} / \mathrm{C} /$ substrate catalysts. The reaction was carried out in a Parr stainless steel autoclave of $300 \mathrm{~mL}$, equipped with baffles (Figure 1). To take into account mass transfer issues, the catalytic samples were tested in powder shape or as entire objects and the activity was compared for some samples. The mode of stirring used was function of the catalyst shape. A gas-inducing turbine at a stirring rate of $1100 \mathrm{rpm}$ was used for catalytic powders (Family a: $\mathrm{Pd} / \mathrm{C}$ or crushed $\mathrm{Pd} / \mathrm{C} /$ monolith). Complex shapes (Family b: $\mathrm{Pd} / \mathrm{C} /$ foam, $\mathrm{Pd} / \mathrm{C} /$ monolith) were installed on a grid above the anchored magnetic rod and the mixture was stirred at $1100 \mathrm{rpm}$. The catalytic material was first contacted with $113 \mathrm{~mL}$ ethanol:water (90:10) and hydrogen (3 bar) at the reaction temperature $\left(40{ }^{\circ} \mathrm{C}\right) .2 \mathrm{~mL}$ nitrobenzene (Acros) were then added to the mixture. During the reaction, hydrogen was fed to the semi-batch reactor at constant pressure (3 bar) via a pressure regulator. It was supplied from an upstream calibrated reservoir. The pressure decrease in this reservoir at the beginning of the reaction yielded the initial hydrogen consumption rate and thus the initial reaction rate.

\subsection{Sample naming}

The carbon coated samples have been named according to the following rules: the first character concerns the substrate name ( $\mathrm{M}$ for monolith, $\mathrm{P}$ for plate and $\mathrm{F}$ for foam), the second one concerns the method of carbon coating ( $\mathrm{P}$ for polymerisation and $\mathrm{S}$ for suspension) and the third character is the numbering of the samples in our experiments. For the impregnated samples, 
(a) Gas-inducing stirring mode

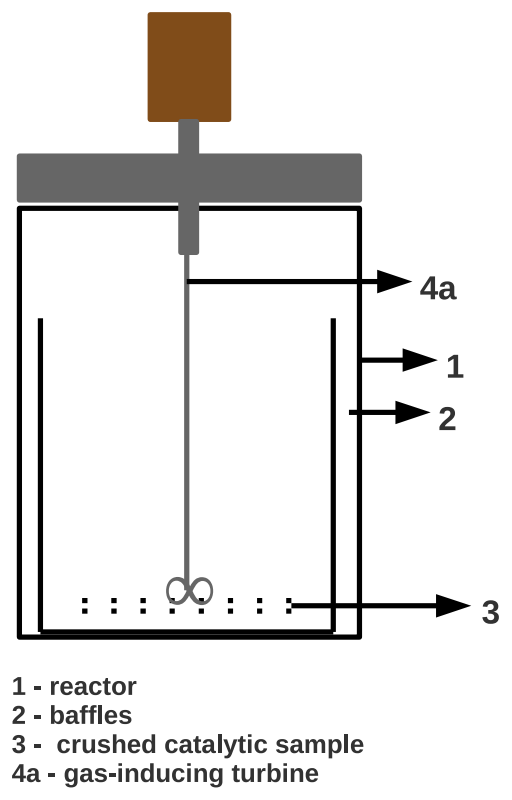

(b) Magnetic stirring mode

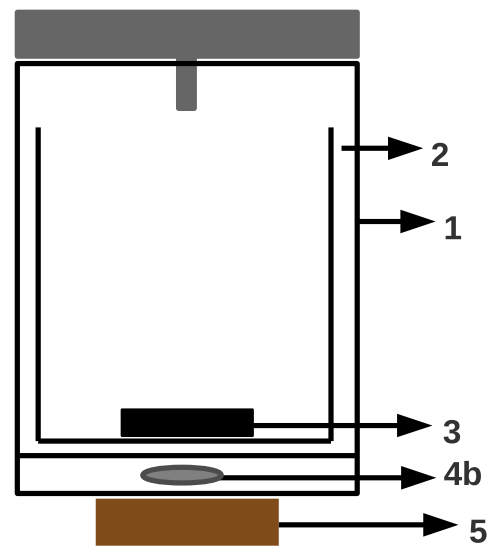

1 - reactor

2 - baffles

3 - uncrushed sample

4b - anchored magnetic rod

5- magnetic stirrer

Figure 1: Nitrobenzene hydrogenation reactor with two stirring modes (a - gas-inducing stirring mode and b - magnetic stirring).

the prefix "Pd/" has been added. For example, Pd/MP6 is a monolith coated with carbon by the polymerisation method and impregnated with palladium (6th sample of the same method). $\mathrm{Pd} / \mathrm{M}$ is a monolith directly impregnated with palladium (no carbon), $\mathrm{Pd} / \mathrm{XC} 72$ corresponds to carbon black powder impregnated with palladium and $\mathrm{Pd} / \mathrm{JM}$ is a Johnson Matthey catalyst. In the suspension method, we have named "Susp" a simple suspension with XC72, water and Triton X-100, "Susp+D" the same suspension with dextrine and "Susp+S" the suspension with sucrose.

\section{Coating results}

\subsection{Optimisation of the coating by the polymerisation method}

The preliminary experiments concerning the search of the appropriate polymer formulation to coat stainless steel objects were performed using stainless steel plates rather than structured objects. The objective was to better quantify the homogeneity of the coating and its adherence.

Many plates were coated by a polymeric solution. In order to optimize the 
coating, the effect of several parameters was studied: the pretreatment of SS, the use of a texturing agent (PEG or EG) and the polymerisation duration. All the data have been collected in Table 1 . The symbols used to characterize the adherence and the homogeneity of carbon coatings could be quantified as follow : concerning the adherence, ultra-sonic treatments have been performed. Symbol ++ means that coating adherence was over $95 \%$, symbol + is used for adherence over $90 \%$, symbol +- for adherence over $70 \%$, symbol for adherence less than $50 \%$ and symbol -- means that adherence was lower than 20\%. The homogeneity factor is more qualitative. It is a result of visual observations and thickness homogeneity measurements. The symbol ++ is used when $100 \%$ of the plate surface is covered and when more than $95 \%$ of the thickness is homogeneous. The symbol + is used when $100 \%$ of the plate surface is covered and when more than $90 \%$ of the thickness is homogeneous. The symbol +- is related to a surface covered at more than $95 \%$ with a thickness homogeneity superior at $85 \%$. The symbol - is used when less than $90 \%$ of the plate surface is covered by carbon coating whatever the thickness homogeneity and the symbol -- is deserved to plates with a surface covering less than $85 \%$ whatever the thickness homogeneity. 


\begin{tabular}{ccccccc}
$\begin{array}{c}\text { Sample } \\
\text { number }\end{array}$ & $\begin{array}{c}\text { SS } \\
\text { pretreatment }\end{array}$ & $\begin{array}{c}\text { Texturing } \\
\text { agent }\end{array}$ & $\begin{array}{c}\text { Polymerisation } \\
\text { duration }(\mathrm{min})\end{array}$ & Adherence & Homogeneity & $\begin{array}{c}\text { Thickness } \\
\text { um }\end{array}$ \\
\hline PP1 & No & PEG & 40 & - & +- & n.a. \\
PP2 & No & PEG & 60 & - & - & $5-10$ \\
PP3 & No & PEG & 80 & - & - & n.a. \\
PP4 & No & - & 40 & - & -- & 20 \\
PP5 & No & - & 60 & -- & -- & $20-35$ \\
PP6 & No & - & 80 & -- & - & n.a. \\
PP7 and PP8 & No & EG & 40 & + & +- & n.a. \\
PP9, PP10, PP11 and PP12 & Yes & EG & 40 & ++ & ++ & 5 \\
PP13 and PP14 & No & EG & 60 & +- & +- & 8 \\
PP15, PP16, PP17 and PP18 & Yes & EG & 60 & + & + & $5-8$ \\
PP19 & No & EG & 80 & +- & +- & 10 \\
\hline
\end{tabular}

Table 1: Effect of polymeric solution composition, stainless steel (SS) pretreatment and polymerisation duration on coating adherence, homogeneity and thickness. 
First of all, the effect of pretreatment is clearly demonstrated by comparing the adherence of the carbon layer on samples PP8 and PP9 or on samples PP14 and PP15. This thermal and chemical pretreatment allows to better spread the polymer on the substrate surface. Thus, the homogeneity of the coating is better and an adherence increase is observed (see (c) in Figure 2 ). This kind of pretreatment chemically modifies the stainless steel surface [22] which probably leads to a modification of the wetting properties of the surface and an increase of bonds between the coating and the stainless steel surface.

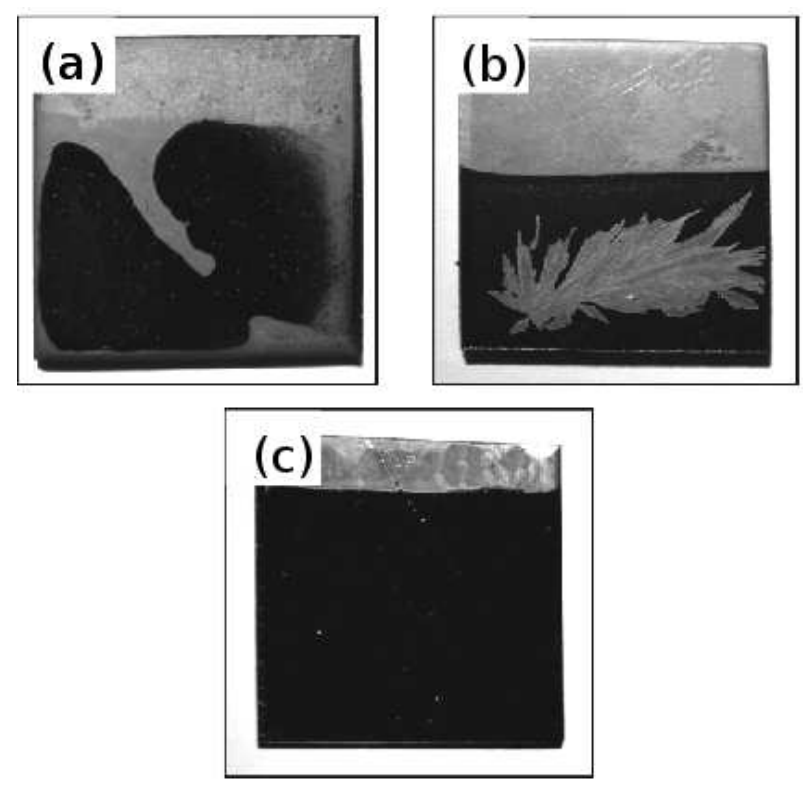

Figure 2: Pictures of samples without $(\mathrm{a}, \mathrm{b})$ and with stainless steel pretreatment (c).

Then, the role of the texturing agent is shown by comparing the samples prepared without any additive and with EG or PEG. Without any additive, the polymerisation is fast and leads to thick but non-uniform and non-adherent coatings (samples PP4 to PP6). In term of adherence, the comparison of EG and PEG is clearly in favour of EG (compare samples PP7 and PP1 or samples PP13 and PP2). The carbon layer is thin, but uniform and adherent. Indeed, after tests $\mathrm{A}$ and $\mathrm{B}$, the adherence is up to $90 \%(++)$.

Concerning the polymerisation duration, it has to be adapted to the object to coat. For flat plates, 40 or 60 minutes are appropriate leading to 
viscosities of ca. $10 \mathrm{mPas}$. Beyond this duration, coating thickness increases thus leading to less adherent coatings. In the case of structured substrates, less viscous solutions (1 mPas) should be preferred in order to avoid clogging.

\subsection{Coating of structured substrates by the polymerisation method}

Different shapes have been covered with carbon according to the polymerisation method (see example in Figure 3). Using the optimal experimental conditions described above, the obtained objects are uniformly coated and the layer is well-anchored. When the substrate is a foam, the polymeric solution and subsequently the carbon layer are located on the foam structure, no agglomeration in the open cells of the foam was observed.

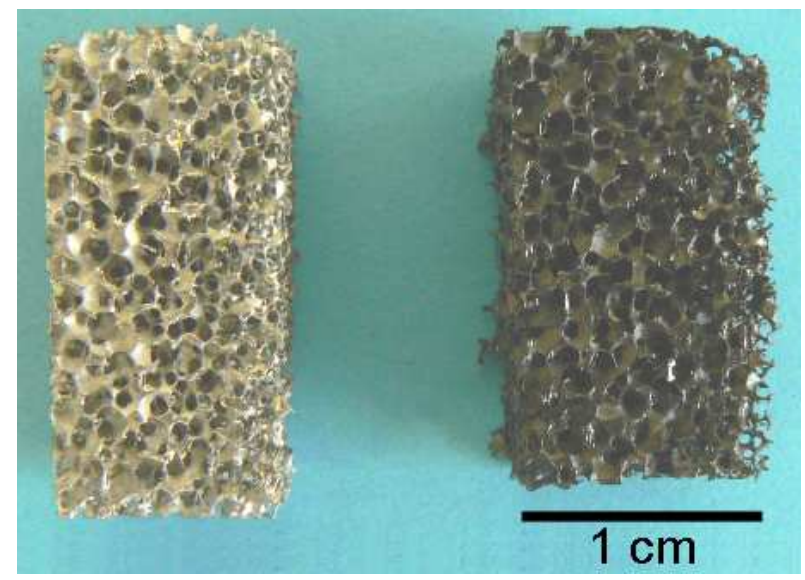

Figure 3: Stainless steel foam before (left) and after carbon coating (right) by the polymerisation method.

\subsection{Suspension method}

The pretreatments of the substrates were the same than before the polymerisation method. The suspension of carbon black, water and additives was prepared as described previously. The role of an ultrasonic treatment of the suspension was demonstrated by analysing the particle size distribution. Combined to ball-milling the suspension during 15 minutes, ultrasonic treatment resulted in a rapid decrease of the particle diameter $\left(\mathrm{D}_{50}=1 \mu \mathrm{m}\right)$. Among several surfactants, Triton X-100 was chosen because it allowed to obtain the most homogeneous and stable suspension. The combination of ultrasonic treatment and Triton X-100 resulted in small, non-settling particles 
in the suspension.

After dip-coating, drying and calcinating, the weight increase of the cordierite pieces was $2 \pm 0.3 \mathrm{wt} \%$. The carbon weight loss after adherence test $\mathrm{A}$ was $10 w t \%$ but reached $50 w t \%$ after adherence test B.

\begin{tabular}{ccccc}
$\begin{array}{c}\text { Sample } \\
\text { number }\end{array}$ & Substrate & $\begin{array}{c}\text { Additive } \\
\text { and wt\% of the suspension }\end{array}$ & $\begin{array}{c}\text { on substrate } \\
\text { wt } \%\end{array}$ & $\begin{array}{c}\text { Adherence } \\
\%\end{array}$ \\
\hline MS1 & Monolith & No & $2 \%$ & $<50 \%$ \\
MS2 & Monolith & HPC* 400ppm $^{*}$ & $1.2 \%$ & $74 \%$ \\
MS3 & Monolith & Dextrine 0.1\% & $3 \%$ & $74 \%$ \\
MS4-MS5-MS6 & Monolith & Dextrine 2\% & $1.8-2.2 \%$ & $90-98 \%$ \\
MS7 & Monolith & Sucrose 2\% & $1.6 \%$ & $99 \%$ \\
FS1-FS2 & Foam & Dextrine 2\% & $1.2-1.3 \%$ & $73-76 \%$ \\
FS3 & Foam & Sucrose 2\% & $1.4 \%$ & $90 \%$ \\
\hline
\end{tabular}

Table 2: Results obtained with the suspension method. The percentage of adherence is the weight fraction of carbon remaining on the substrate after ultra-sonic adherence tests $\mathrm{A}$ and B. ${ }^{*} \mathrm{HPC}$ for hydroxy-propyl-cellulose

Concerning the use of this method to coat stainless steel or glass objects, the results were unsuccessful. Dextrine and sucrose have been evaluated as additives to increase the carbon adherence on stainless steel substrates. Sucrose has already been described as a possible carbon precursor [23] and was used here as a dispersant. The use of hydroxy-propyl-cellulose was also evaluated but it resulted in foaming suspension, even at very low loading. The addition of dextrine or sucrose increased the adherence of the carbon suspension (see Table 2) and allowed to coat stainless steel substrates (see Figure 4). As shown on Figures 4 and 5, the carbon layer was uniform and did not plug the foam open cells. Figure 5 shows SEM pictures obtained on stainless steel foam before and after carbon coating by suspension method. The samples were cut before analyses in order to observe their inner structure. Figure 6 exhibits a cross section SEM picture obtained on cordierite monolith after $\mathrm{Pd} / \mathrm{C}$ coating by suspension method. On this sample, the carbon thickness reached $12 \mu \mathrm{m}$. 


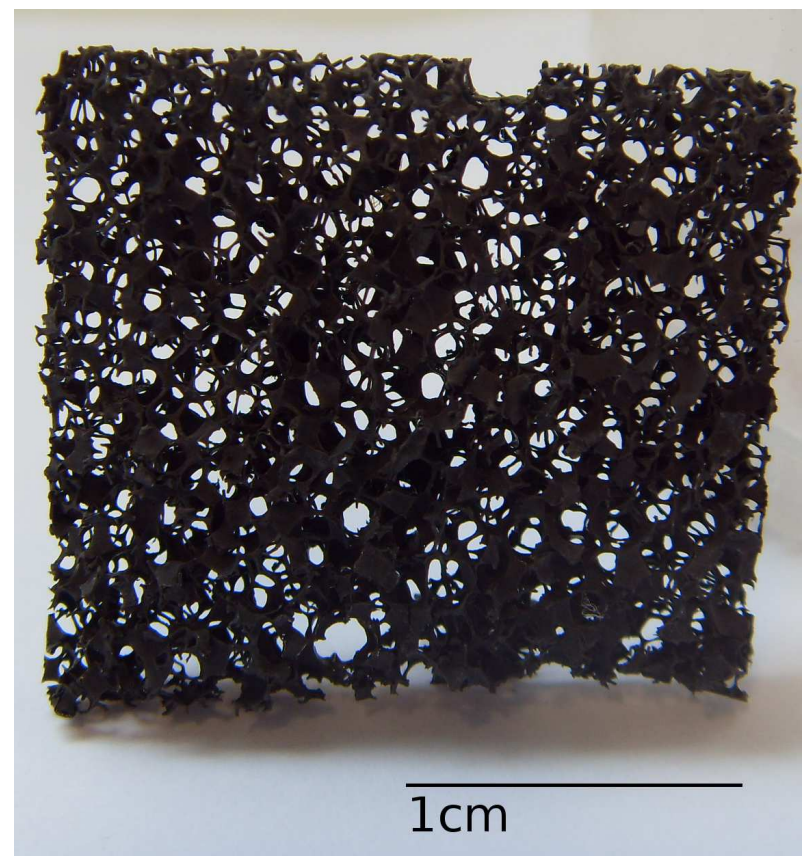

Figure 4: Stainless steel foam after carbon coating (suspension method).

\section{Characterisation and catalytic activity of carbon-coated mono- liths}

\subsection{Role of activation in the polymerisation method}

The acid functions on the surface of the carbon-coated monoliths by the polymerisation method have been measured by acid-base titration. The results are presented in Table 3. The chemical oxidation treatments have allowed to increase the surface acid functions. $\mathrm{H}_{2} \mathrm{O}_{2}$ seems to be an appropriate treatment to generate acid functions on the carbon.

\begin{tabular}{cccc}
$\begin{array}{c}\text { Sample } \\
\text { number }\end{array}$ & $\begin{array}{c}\text { Mass of } \\
\text { carbon }(\mathrm{wt} \%)\end{array}$ & Treatment & $\begin{array}{c}\text { Acid functions } \\
\mathrm{mmol} / \mathrm{g}\end{array}$ \\
\hline MP1 & 4.3 & $\mathrm{H}_{2} \mathrm{O}_{2}$ & 2.3 \\
MP2 & 4.5 & $\mathrm{No}_{0}$ & 0.8 \\
\hline
\end{tabular}

Table 3: Results of titration of the surface acid functions of carbon coatings -the acid functions of the cordierite support have been deduced. 

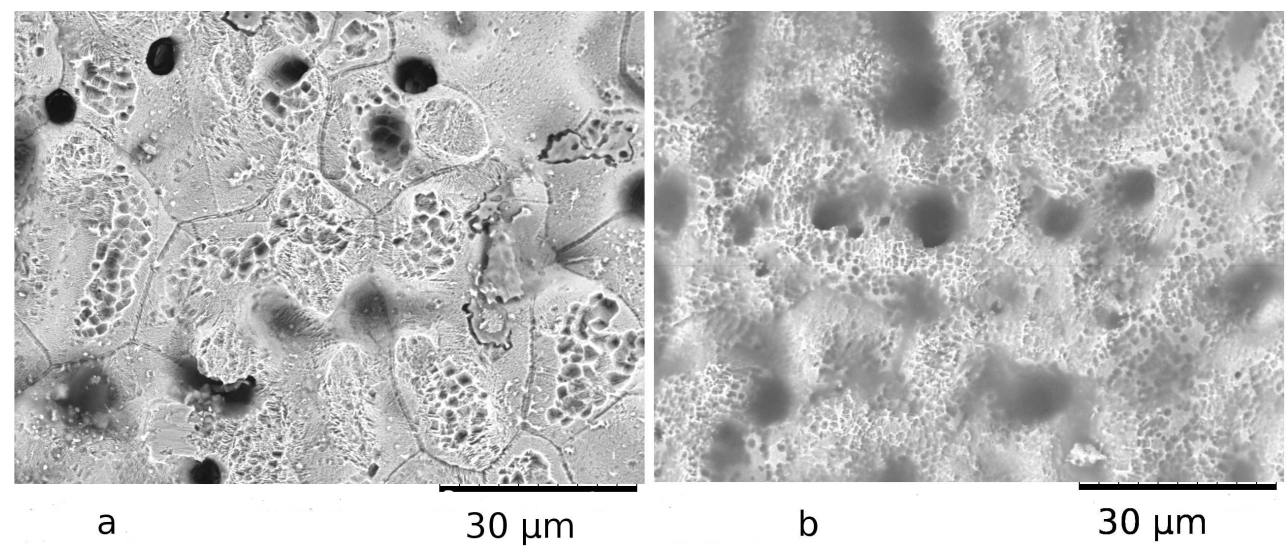

Figure 5: SEM pictures of stainless steel foam before (a) and after (b) carbon coating (suspension method with $2 \%$ dextrine).

\subsection{Surface area measurements}

Before measuring the BET surface area of the carbon-coated monoliths, it was checked that the cordierite surface was negligible. The textural properties of the commercial carbon black powder (Vulcan XC72) have been measured as the reference (Table 4). Its BET surface is ca. $200 \mathrm{~m}^{2} / g(C)$ with a mean pore diameter of approximately $7 \mathrm{~nm}$. After impregnation with $\mathrm{Pd}$, the textural properties of the powder stay similar (see ref. $\mathrm{Pd} / \mathrm{XC} 72-1$ ). The coated substrates (monolith or foam), prepared with the suspension method with dextrine (Susp+D, Pd/MS8) also show similar textural properties. Those prepared with sucrose (Susp+S, Pd/MS9) present a significant lower surface area and bigger pores. On the contrary, all coated substrates obtained with the polymerisation method (named "poly" in the table - with various activation methods - air or $\mathrm{H}_{2} \mathrm{O}_{2}$ ) are mainly microporous, with high surface areas and small pores. $\mathrm{H}_{2} \mathrm{O}_{2}$ seemed to be the best activation method in terms of increase of surface area and of acid functions.

\subsection{Nitrobenzene hydrogenation}

\subsubsection{Mass transfer issues and accuracy of measurements}

It was first checked that crushed and uncrushed monolith samples (with their respective appropriate stirring modes) gave similar results (experiments $\mathrm{Pd} / \mathrm{MS} 11$ and $\mathrm{Pd} / \mathrm{MS13})$. Whatever the stirring mode, the reaction rate $(\mathrm{mol} / \mathrm{s})$ was also found to be proportional to the weight of catalyst (not 


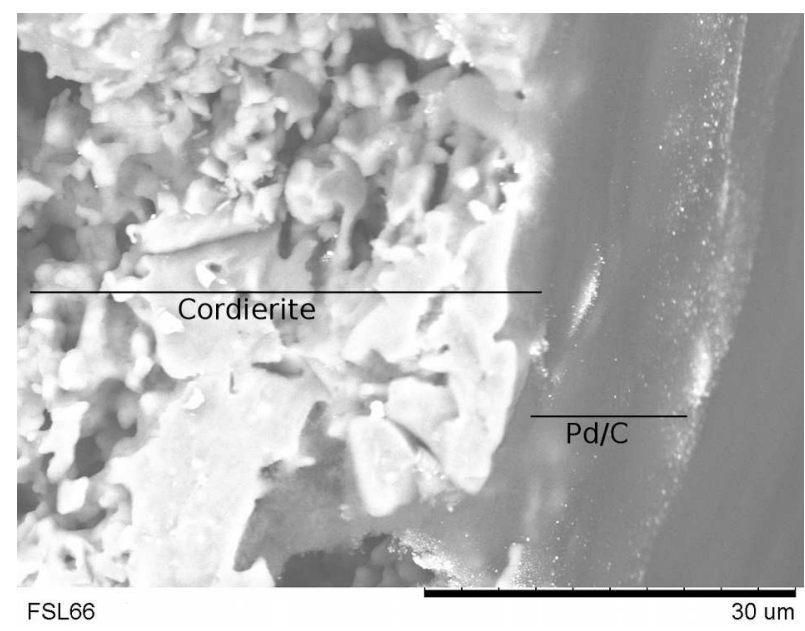

Figure 6: Cross section SEM picture of cordierite monolith after Pd/C coating by suspension method.

presented). It was expected that rate measurements were likely performed in chemical regime with the absence of significant mass transfer phenomena.

Important deviations between samples with identical preparation were nevertheless recorded. They were due to cumulative uncertainties in the carbon weight of the samples $( \pm 10 \%)$, their palladium content $( \pm 20 \%)$ and also the estimation of the reaction rate $( \pm 20 \%)$. Then, the standard deviation of initial hydrogen consumption rates (per gram of carbon or per gram of Pd) can reach $50 \%$.

\subsubsection{Hydrogenation results}

All the experiments of nitrobenzene hydrogenation have been collected in Table 5. Before comparing the catalytic activity of the $\mathrm{Pd} /$ carbon/monolith samples, reference tests were performed with $\mathrm{Pd} / \mathrm{C}$ powder. The first one is a commercial catalyst. The second one (Pd/XC72-2) has been prepared with the same carbon powder used for suspension preparation (Vulcan XC72), by impregnation with palladium chloride, leading to a $2 \mathrm{wt} \% \mathrm{Pd} / \mathrm{C}$. The commercial catalyst shows an activity one order of magnitude higher than the home-made one. This is probably due to the nature of the carbon used: activated charcoal is indeed a better catalyst support than carbon black. The data obtained for coated samples should be compared to Pd/XC72-2. Blank tests were also performed with $\mathrm{Pd} / \mathrm{M}$ to ensure that the dispersion of $\mathrm{Pd}$ on the ceramic was negligible. The results obtained with Pd supported on 


\begin{tabular}{cccccc}
$\begin{array}{c}\text { Sample } \\
\text { number }\end{array}$ & Substrate & Coating method & $\begin{array}{c}\text { wt\%Pd } \\
\text { on } \mathrm{C}\end{array}$ & $\begin{array}{c}\text { BET surface } \\
\mathrm{m}^{2} / g(C)\end{array}$ & $\begin{array}{c}\text { Pore diameter } \\
\text { nm }\end{array}$ \\
\hline XC72 & Vulcan powder & - & 0 & 224 & 6.6 \\
Pd/XC72-1 & Vulcan powder & - & 4.6 & 184 & 6.7 \\
Pd/MS8 & Monolith & Susp+D & n.a. & 212 & 7.7 \\
Pd/MS9 & Monolith & Susp+S & n.a. & 161 & 9.8 \\
MP1-MP2 & Monolith & poly & 0 & $480 \pm 40$ & 2.3 \\
MP3-MP4 & Monolith & poly-air & 0 & $320 \pm 60$ & $2.5 \pm 0.2$ \\
MP5 & Monolith & poly-air- $\mathrm{H}_{2} \mathrm{O}_{2}$ & 0 & 254 & n.d. \\
MP6-MP7 & Monolith & poly- $\mathrm{H}_{2} \mathrm{O}_{2}$ & 0 & $1100 \pm 400$ & $2.1 \pm 0.1$ \\
MP8 & Monolith & poly-air $/ \mathrm{H}_{2} \mathrm{O}$ & 0 & 14 & n.d. \\
\hline
\end{tabular}

Table 4: Measurements of BET surface and mean pore diameter of the carbon coatings (the surface values are expressed per gram of carbon).

carbon-coated monoliths strongly depend on the method used to obtain the carbon coating. The results highlighted that Vulcan-coated monolith is a much better catalyst support than resin-coated monolith for nitrobenzene hydrogenation. All the carbon (from resin) activation attempts did not allow to increase the activity of the resulting $\mathrm{Pd} / \mathrm{C} /$ monolith. All the samples obtained with the polymerisation method have similar or lower activity than the $\mathrm{Pd} /$ monolith sample $(\mathrm{Pd} / \mathrm{M}$, with no carbon at all). As the pore diameter of the polymer-coated samples is low, the palladium particles are perhaps not accessible to nitrobenzene (molecular diameter of $0.6 \mathrm{~nm}$ [24]). Another reaction could perhaps lead to different results.

Concerning Vulcan-coated samples, they all exhibit a catalyst activity in the same order of magnitude than the corresponding $\mathrm{Pd} /$ Vulcan powder (Pd/XC72-2 or Pd/XC72-1). For the samples obtained by suspension method, the addition of dextrine or sucrose does not affect the catalytic activity of the resulting catalyst. The dispersion of the results can be accounted for by uncertainties in the $\mathrm{Pd}$ content as detailed in the previous paragraph. Note that the activities obtained with Vulcan-coatings are nevertheless one order of magnitude lower than those measured with a commercial catalyst $(\mathrm{Pd} / \mathrm{JM})$. 


\begin{tabular}{|c|c|c|c|c|c|c|c|c|}
\hline $\begin{array}{l}\text { Sample } \\
\text { number }\end{array}$ & Family & Substrate & $\begin{array}{l}\text { Coating } \\
\text { Method }\end{array}$ & $\begin{array}{c}\mathrm{C} \% \\
g / 100 g_{\text {substrate }}\end{array}$ & $\begin{array}{c}\text { wt } \% \mathrm{Pd} \\
\text { on } \mathrm{C}\end{array}$ & $\begin{array}{c}\text { ini. } \mathrm{H}_{2} \text { cons. } \\
\text { pmol.s } s^{-1} \cdot g_{\text {substrate }}^{-1}\end{array}$ & $\begin{array}{l}\text { ini. } \mathrm{H}_{2} \text { cons. } \\
\text { } \text { mol. } s^{-1} \cdot g_{C}^{-1}\end{array}$ & $\begin{array}{l}\text { ini. } \mathrm{H}_{2} \text { cons. } \\
\text { mmol.s } s^{-1} \cdot g_{P d}^{-1}\end{array}$ \\
\hline $\mathrm{Pd} / \mathrm{JM}$ & $\mathrm{a}$ & Charcoal powder & - & 100 & 5 & & 2700 & 55 \\
\hline $\mathrm{Pd} / \mathrm{XC} 72-1$ & $\mathrm{a}$ & Vulcan powder & - & 100 & 4.6 & - & $125^{*}$ & $3^{*}$ \\
\hline $\mathrm{Pd} / \mathrm{XC} 72-2$ & $\mathrm{a}$ & Vulcan powder & - & 100 & 1.7 & - & $50-100$ & $2-5$ \\
\hline $\mathrm{Pd} / \mathrm{M}$ & $\mathrm{a}$ & Monolith & - & 0 & 0.1 & 1 & - & 0.9 \\
\hline $\mathrm{Pd} / \mathrm{MP} 1$ & $\mathrm{a}$ & Monolith & poly & 5.8 & 2 & 0.5 & 9 & 0.4 \\
\hline $\mathrm{Pd} / \mathrm{MP} 3$ & a & Monolith & poly-air & 5.5 & 1.9 & 0.8 & 15 & 0.7 \\
\hline $\mathrm{Pd} / \mathrm{MP} 5$ & a & Monolith & poly-air- $\mathrm{H}_{2} \mathrm{O}_{2}$ & 5.9 & 0.1 & 0 & 0 & 0 \\
\hline $\mathrm{Pd} / \mathrm{MP} 6$ & $\mathrm{a}$ & Monolith & poly- $\mathrm{H}_{2} \mathrm{O}_{2}$ & 5.0 & 8.1 & 0.1 & 2 & 0.02 \\
\hline $\mathrm{Pd} / \mathrm{MP} 8$ & $\mathrm{a}$ & Monolith & poly-air $/ \mathrm{H}_{2} \mathrm{O}$ & 6.2 & 9.0 & 0.3 & 4.2 & 0.05 \\
\hline $\mathrm{Pd} / \mathrm{MS} 10$ & a & Monolith & Susp & 1.8 & 2.4 & 5.5 & 300 & 10 \\
\hline $\mathrm{Pd} / \mathrm{MS} 11$ & $\mathrm{a}$ & Monolith & Susp+D & 1.6 & 1 & 0.7 & 43 & 4 \\
\hline $\mathrm{Pd} / \mathrm{MS} 12$ & $\mathrm{~b}$ & Monolith & Susp+D & 1.6 & 1.7 & $4.7^{*}$ & $290 *$ & $17^{*}$ \\
\hline $\mathrm{Pd} / \mathrm{MS} 9$ & $\mathrm{~b}$ & Monolith & Susp $+S$ & 3.0 & n.a. & 1 & 35 & - \\
\hline $\mathrm{Pd} / \mathrm{MS} 13$ & $\mathrm{~b}$ & Monolith & Susp+D & 1.9 & 1.1 & 0.5 & 26 & 2.4 \\
\hline $\mathrm{Pd} / \mathrm{FS} 4$ & $\mathrm{~b}$ & Foam & Susp+D & 1.4 & 13 & $12^{*}$ & $200^{*}$ & $1.5^{*}$ \\
\hline
\end{tabular}

Table 5: Nitrobenzene hydrogenation at $40{ }^{\circ} \mathrm{C}$ and 3 bar. $*$ estimated values (experiments performed at 12 bars, rates divided by 4$)$. 


\section{Conclusion and perspectives}

Two methods of carbon coating have been compared: one based on the carbonisation of a polymer and the other on a suspension of carbon. The first method leads to adherent layers whatever the substrate but to a poor catalytic activity for nitrobenzene hydrogenation. The second has been optimised to obtain a good adhesion on ceramic and stainless steel substrates. High catalytic activities were measured for nitrobenzene hydrogenation. The difference between both methods seems to be due to different pore size. Pd particles in the small pores of the polymer carbon coatings are probably not accessible to nitrobenzene molecules. The catalytic activity of both coatings could be compared for the transformation of smaller molecules. Further work is also required to evaluate the possible use of suspensions of charcoal, or even of commercial carbon-supported catalysts, instead of carbon black.

\section{Acknowledgements}

The work concerning the polymer method (post-doc fellowship of Philippe Rodriguez) was financially supported by Axelera "Process Intensification WP6" through a collaboration with Rhodia (Pascal PITIOT). Part of the work concerning the suspension method (post-doc fellowship of Florica SimescuLazar) was funded by the EU program POLYCAT, under grant agreement No. CP-IP 246095-2 of the European Community's Seventh Framework Program.

\section{References}

[1] T. A. Nijhuis, A. E. W. Beers, T. Vergunst, I. Hoek, F. Kapteijn, J. A. Moulijn, Preparation of monolithic catalysts, Cat. Rev. - Sci. Eng. 43 (2001) 345-380.

[2] P. Avila, M. Montes, E. E. Miro, Monolithic reactors for environmental applications. A review on preparation technologies, Chem. Eng. J. 109 (2005) 11-36.

[3] V. Meille, Review on methods to deposit catalysts on structured surfaces, Appl. Catal., A 315 (2006) 1-17. 
[4] C. Pijolat, M. Camara, J. Courbat, J. Viricelle, D. Briand, N. de Rooij, Application of carbon nano-powders for a gas micro-preconcentrator, Sensors and Actuators B: Chemical 127 (1) (2007) 179-185.

[5] K. Yoshida, K. Matsukawa, M. Imai, T. Yano, Formation of carbon coating on $\mathrm{SiC}$ fiber for two-dimensional $\mathrm{SiC}_{f} / \mathrm{SiC}$ composites by electrophoretic deposition, Materials Science and Engineering: B 161 (1-3) (2009) 188-192.

[6] E. E. Hucke, Methods of producing carbonaceous bodies and the products thereof, Patent US 3859421 (3 859 421).

[7] T. Vergunst, M. J. G. Linders, F. Kapteijn, J. A. Moulijn, Carbon based monolithic structures, Catal. Rev. - Sci. Eng. 43 (2001) 291-314.

[8] E. Crezee, A. Barendregt, F. Kapteijn, J. A. Moulijn, Carbon coated monolithic catalysts in the selective oxidation of cyclohexanone, Catal. Today 69 (2001) 283-290.

[9] E. A. Dawson, P. A. Barnes, M. J. Chinn, Preparation and characterisation of carbon-coated ceramic foams for organic vapour adsorption, Carbon 44 (2006) 1189-1197.

[10] F. J. Maldonado-Hodar, S. Morales-Torres, F. Ribeiro, E. Ribeiro Silva, A. F. Perez-Cadenas, F. Carrasco-Marin, F. A. Costa Oliveira, Development of carbon coatings for cordierite foams: An alternative to cordierite honeycombs, Langmuir 24 (2008) 3267-3273.

[11] S. Schimpf, M. Bron, P. Claus, Carbon-coated microstructured reactors for heterogeneously catalyzed gas phase reactions: influence of coating procedure on catalytic activity and selectivity, Chem. Eng. J. 101 (2004) $11-16$.

[12] M. Acharya, H. C. Foley, Spray-coating of nanoporous carbon membranes for air separation, J. Membr. Sci. 161 (1999) 1-5.

[13] S. Hajiesmaili, S. Josset, D. Bégin, C. Pham-Huu, N. Keller, V. Keller, 3D solid carbon foam-based photocatalytic materials for vapor phase flow-through structured photoreactors, Applied Catalysis A: General 382 (1) (2010) 122-130. 
[14] E. Garcia-Bordeje, F. Kapteijn, J. A. Moulijn, Preparation and characterisation aspects of carbon-coated monoliths, Catal. Today 69 (2001) $357-363$.

[15] B. Gong, R. Wang, B. Lin, F. Xie, X. Yu, K. Wei, Preparation of carbon nanotubes (CNTs)-Cordierite monoliths by catalytic chemical vapor deposition as catalyst supports for ammonia synthesis, Catalysis Letters $122(3-4)$ (2008) 287-294.

[16] A. Agiral, L. Lefferts, J. H. Gardeniers, In situ CVD of carbon nanofibers in a microreactor, Catalysis Today 150 (1-2) (2010) 128-132.

[17] S. Morales-Torres, A. F. Perez-Cadenas, F. Kapteijn, F. CarrascoMarin, F. J. Maldonado-Hodar, J. A. Moulijn, Palladium and platinum catalysts supported on carbon nanofiber coated monoliths for lowtemperature combustion of BTX, Appl. Catal., B 89 (2009) 411-419.

[18] L. Martinez-Latorre, S. Armenise, E. Garcia-Bordeje, Temperaturemediated control of the growth of an entangled carbon nanofiber layer on stainless steel micro-structured reactors, Carbon 48 (3) (2010) 20472056 .

[19] R. M. Machado, R. R. Broekhuis, A. F. Nordquist, B. P. Roy, S. R. Carney, Applying monolith reactors for hydrogenations in the production of specialty chemicals-process and economic considerations, Catal. Today 105 (2005) 305-317.

[20] P. Rodriguez, V. Meille, S. Pallier, M. A. Al Sawah, Deposition and characterisation of $\mathrm{TiO}_{2}$ coatings on various supports for structured (photo)catalytic reactors, Appl. Catal., A 360 (2009) 154-162.

[21] A. Contescu, C. Contescu, K. Putyera, J. Schwarz, Surface acidity of carbons characterized by their continuous pK distribution and boehm titration, Carbon 35 (1) (1997) 83-94.

[22] T. Giornelli, A. Lofberg, E. Bordes-Richard, Preparation and characterization of $\mathrm{VO}_{x} / \mathrm{TiO}_{2}$ catalytic coatings on stainless steel plates for structured catalytic reactors, Appl. Catal., A 305 (2006) 197-203. 
[23] K. M. de Lathouder, D. Lozano-Castello, A. Linares-Solano, F. Kapteijn, J. A. Moulijn, Carbon coated monoliths as support material for a lactase from aspergillus oryzae: Characterization and design of the carbon carriers, Carbon 44 (2006) 3053-3063.

[24] Y. Marcus, The Properties of Solvents, vol. 4, John Wiley \& Sons Ltd, 1999. 